\title{
Evaluation of the symptoms and treatment prescribed to hospitalized patients
}

\author{
Mariana da Silva Roldi ${ }^{1 *}$, Rachel Duarte Moritz ${ }^{2}$ \\ ${ }^{1}$ Medical Student, Universidade Federal de Santa Catarina (UFSC), Florianópolis, SC, Brazil \\ ${ }^{2}$ MD degree from UFSC, MSc in Medical Sciences, PhD in Production Engineering. Professor, Department of Internal Medicine, UFSC, Florianópolis, SC, Brazil
}

Study conducted at Hospital Universitário Professor Polydoro Ernani de São Thiago, Universidade Federal de Santa Catarina (HU-UFSC), Florianópolis, SC, Brazil

Article received: $10 / 27 / 2014$ Accepted for publication: 4/27/2015

*Correspondence: Address: Rua Guilherme Pugsley, 2650 Água Verde Curitiba, PR - Brazil Postal code: 80610-300 marianaroldi@hotmail.com

\section{SUMMARY}

Objective: Evaluation of the presence of symptoms and suitability in the treatment of patients admitted to medical wards at HU-UFSC. Identification of patients eligible for palliative care (PC).

Method: A prospective cohort study, which evaluated patients in the first 48 hours of hospitalization (D1) and after 48 hours (D2). On D1, palliative performance and symptom assessment scales were applied (PPS/ESAS). The treatment established for the control of detected symptoms was also identified. On D2, the ESAS scale was applied again, and the medical prescription reviewed. When the presence of severe symptoms was found, the attending physician was informed. Patients who presented PPS $\leq 60$ were eligible for PC prioritization. For statistical analysis Student's $t$ and $\chi^{2}$ tests were used.

Results: 168 patients were studied. Of these, $26.8 \%$ had PPS $\leq 60$. PC was described in one medical chart. Patients with mild symptoms reported significant worsening in the second evaluation, especially worsening in pain $(32.3 \%)$ and well-being (49.3\%). Symptoms considered severe showed significant improvement. There was no control of pain reported as moderate. Prescriptions for pain control were predominantly "if necessary", prevailing the use of non-opioid analgesics and weak opioids. The attending physician was informed of 116 (69\%) patients with ESAS score $\geq 4$.

Conclusion: The control of symptoms, especially those considered mild, was unsatisfactory. Drug prescription was inadequate to control pain, and non-existent for some reported symptoms. There was no adequate prioritization of PC. There is a need for optimization and dissemination of PC among health professionals.

Keywords: palliative care, symptom assessment, scales, pain.

\section{INTRODUCTION}

The profound structural transformations that the Brazilian population has undergone since the 1930s, derived from an epidemiological transition with changes in mortality and fertility rates, has resulted in a population aging process ${ }^{1}$ and consequent increase in the prevalence of chronic degenerative diseases, including metabolic diseases (such as diabetes and obesity), cardio-cerebrovascular diseases, cancer, and more. ${ }^{2}$ Chronic degenerative diseases are illnesses that require greater monitoring, evaluation and long-term interventions, with the need for major human and material resources. ${ }^{3-6}$
The majority of patients with chronic diseases in advanced stages, whether oncologic or non-oncologic, present multiple physical and psychological symptoms that produce a significant decrease in their quality of life. ${ }^{7}$ Physicians often underestimate the symptoms reported by the patient and, therefore, do not offer proper treatment. ${ }^{3-9}$ Studies show that patients who die in hospitals have poorly controlled symptoms and often suffer from pain, dyspnea and restlessness. ${ }^{9-12}$

Based on the perspective that patients with chronic degenerative diseases have a major reduction in quality of life, knowledge of palliative care is essential. ${ }^{9}$ Current- 
ly, palliative care $(\mathrm{PC})$ is conducted by a multidisciplinary team and with the main principles of improving quality of life and positively influencing the course of the disease, integrating the psychological and spiritual aspects of patient care, providing a system of support for both the patient and their family, not accelerating or delaying death, and promoting the relief of pain and other unpleasant symptoms presented by the patient. ${ }^{13-15,20}$

One of the strategies used by the palliative model to obtain relief of patients from suffering is suitable control of symptoms. ${ }^{9,16}$ In order to systematize and facilitate this investigation, certain scales have been created, such as the Edmonton Symptom Assessment System (ESAS), which allows us to assess the presence and intensity of nine symptoms: pain, fatigue, nausea, depression, anxiety, drowsiness, changes in appetite, dyspnea and malaise. ${ }^{3}$ By allowing gradation of such, this scale can also assist the team in monitoring the results obtained with the therapeutic measures implemented. A major limitation of the ESAS scale is the patient's need for communicative integrity. ${ }^{4,9}$ Another tool is the Palliative Performance Scale (PPS) that was created to measure the patient's functional status and validated as one of the weapons for prognosis prediction. ${ }^{17-19}$ It is based on five dimensions: ambulation, activity and evidence of disease, self-care, intake and level of consciousness. This score ranges from 0 to 100 in intervals of 10 points, with higher scores representing a better performance status. ${ }^{17}$

Due to the importance of early identification and appropriate control of the symptoms presented by patients admitted into Hospital Universitário Professor Polydoro Ernani de São Thiago (HU-UFSC), this study was designed to evaluate the presence of symptoms and the adequacy of the treatment prescribed to patients at the HU-UFSC, as well as verifying which patients would be eligible to receive $\mathrm{PC}$ in a preferential manner.

\section{Method}

This is a prospective cohort study, which evaluated a population comprising patients hospitalized in the wards of the HU-UFSC Internal Medicine Clinic during the period from September 2013 to December 2013, after approval by the institution's Ethics Committee (No. 372.167). All patients were aware of the content of the research and signed a consent form. We excluded from the study those who did not agree to participate, or who had neurological damage or organic lesions incapacitating their response to the questionnaire for the evaluation of symptoms (ESAS).

The evaluation of the participants was carried out at two different times: in the first 48 hours of hospitalization
(D1) and 48 hours after the first analysis (D2). On D1, the PPS was applied to the patient with the goal of establishing their functional assessment prior to hospitalization. After use of this instrument, the ESAS was applied in order to identify their symptoms. We subsequently examined the medical prescription, checking if there were specific therapeutic measures for the control of the symptoms detected. As for pain control, it was observed whether there was prescription for any non-opioid analgesics, nonsteroidal anti-inflammatory drugs (NSAIDs) or opioids. For treatment of asthenia, the use of corticotherapy, hormone therapy or blood transfusion was verified, while for the treatment of nausea the use of metoclopramide, ondansetron or dimenhydrinate was noted. In relation to depression and anxiety the administration of antidepressants, anti-anxiety drugs or psychostimulants was noted. As for the control of anorexia, food stimulus or the presence of a nasogastric tube was analyzed. Oxygen therapy, bronchodilators or nebulization were checked with regard to the control of dyspnea. For the treatment of constipation, we verified whether there was any dietary guidance or the use of laxatives such as mineral oil, lactulose or fleet enema. On D2, the ESAS was reapplied, and the medical prescription to the patient on that day was reviewed. In cases where the symptoms had worsened, or were referred to as moderate or severe (ESAS $\geq 4$ ), the researcher contacted the patient's attending physician, so that they would be aware of the fact.

Patients were grouped according to the intensity of each symptom investigated, and these were classified according to the ESAS score: 0 to 3 - mild/absent symptoms; 4 to 6 - moderate; 7 to 10 - severe.

The comorbidities investigated were hypertension, diabetes, thyroid disease, liver diseases, non-dialytic kidney diseases and HIV.

Patients who presented a PPS $\leq 60$ were indicated as being eligible for prioritization of palliative are.

For statistical analysis we used Student's t-test (on Windows Excel) for quantitative variables, and $\chi^{2}$ for qualitative variables (using Epi-Info 6 software). The level of statistical significance adopted was 5\% ( $\mathrm{p}<0.05)$.

\section{Results}

In the period of the study, 201 patients were evaluated. Two of these refused to participate in the survey, four were not interviewed due to organic changes that prevented communication (one deaf, two tracheostomies and one intubation), and five due to change in level of consciousness. Another 22 patients were eliminated because they received a discharge from hospital before the second evaluation period of the study. 
There were 168 patients eligible for the study; 99 (58.9\%) were men and 69 women (41.1\%). The age ranged from 16 to 86 years, with an average of $55.7 \pm 16.38$ years. Hospital admission was undertaken through the emergency department in 101 cases (60.1\%), from outpatient clinics in 62 (36.9\%) and hospital transfer in $5(3 \%) .118$ patients $(70.2 \%)$ presented some comorbidity, and 41 (37.4\%) of these had more than one comorbidity concomitantly. The PPS analysis showed a significant relationship between age and PPS score $\leq 60$. The clinical and demographic characteristics of the patients are shown in Table 1 .

TABLE 1 Clinical and epidemiological profile of the study participants.

$\begin{array}{llll}\text { Age }<60 & \text { Age } \geq 60 & \text { Statistical } & \text { Total } \\ \text { years } & \text { years } & \text { analysis } & N(\%) \\ N(\%) & N(\%) & \left(\chi^{2}\right) & \end{array}$

\begin{tabular}{|c|c|c|c|c|}
\hline Gender & & & & \\
\hline Female & $38(22.6)$ & $31(18.5)$ & \multirow[t]{2}{*}{ NS } & $69(41.1)$ \\
\hline Male & $51(30.3)$ & $48(28.6)$ & & $99(58.9)$ \\
\hline Acute disease & $28(16.7)$ & $26(15.4)$ & NS & $54(32.1)$ \\
\hline $\begin{array}{l}\text { Chronic } \\
\text { degenerative } \\
\text { disease }\end{array}$ & $61(36.3)$ & $53(31.6)$ & \multirow[t]{3}{*}{ NS } & $114(67.9)$ \\
\hline Malignancy & $13(7.80)$ & $17(10.1)$ & & $30(17.9)$ \\
\hline Non-malignancy & $48(28.5)$ & $36(21.5)$ & & $84(50.0)$ \\
\hline PPS $>60$ & $73(43.5)$ & $50(29.7)$ & \multirow[t]{2}{*}{+} & $123(73.2)$ \\
\hline $\mathrm{PPS} \leq 60$ & $16(9.50)$ & $29(17.3)$ & & $45(26.8)$ \\
\hline \multicolumn{5}{|l|}{ Progression } \\
\hline Death & $5(3.00)$ & $5(3.00)$ & \multirow[t]{3}{*}{ NS } & $10(6.00)$ \\
\hline $\begin{array}{l}\text { Hospital } \\
\text { discharge }\end{array}$ & $84(50.0)$ & $71(42.3)$ & & $155(92.3)$ \\
\hline $\begin{array}{l}\text { Remain } \\
\text { unchanged }\end{array}$ & $2(1.20)$ & $1(0.50)$ & & $3(1.70)$ \\
\hline
\end{tabular}

It was noted that, although 45 patients (26.8\%) presented PPS scores less than or equal to 60 , the need for palliative care was only explicit in the medical records of one patient.

Regarding symptoms, it was noted that all of those listed as absent or mild on the first interview day showed significant worsening $(\mathrm{p}<0.005)$ in the second stage of this study. For patients with mild pain (102 patients), 32.3\% had an increase in pain, with $51.5 \%$ referring moderate pain and $27.2 \%$ severe pain. For those with mild fatigue (95 patients), $27.3 \%$ presented worsening. $14.6 \%$ (22 patients) reported worsening of nausea and $15.4 \%$ (19 patients) worsening of depression. $26 \%$ of the respondents (18 patients) referred worsening of anxiety, worsening of sleepiness in $23.6 \%$ (31 patients), and worsening of appetite in 25\% (27 patients), as well as worsening of dyspnea in 19\% (22 patients) and of general wellbeing in $49.3 \%$ (40 patients).

For the symptoms considered moderate, on D2 there was a significant improvement $(\mathrm{p}<0.05)$ in fatigue, anxiety, dyspnea and wellbeing.

As for severe symptoms, we noted a significant difference $(p<0.005)$ in the intensity of all the symptoms investigated between the two evaluation days, with many obtaining important relief. ${ }^{1}$ In the second evaluation, $57.5 \%$ (19) of patients with severe symptoms had a decrease in pain; in $70 \%$ (28 patients) there was an improvement of fatigue; in $75 \%$ (six patients) there was a decrease in nausea; in $72.7 \%$ (16 patients) there was an improvement of dyspnea; in $54.5 \%$ (12 patients) there was an improvement of depression and in $46.1 \%$ (30 patients) there was an improvement of anxiety. It was also noted that $66.6 \%$ (14 patients) reported an improvement of drowsiness, $51.8 \%$ (14 patients) of appetite, and 68\% (17 patients) felt greater well-being. The figure below shows the progression of symptoms in the two phases of the study (Figure 1).

The analysis of the prescriptions showed that in relation to the control of pain and nausea (in all degrees of intensity - mild, moderate and severe), most patients only had medication prescribed as "if necessary." Regarding other symptoms, such as fatigue, depression, anxiety, dyspnea (in all degrees of intensity), the absence of prescription for the control of such predominated. All patients who reported constipation referred it as severe, but treatment was given only to $34.3 \%$ of patients with this complaint (23 patients) (Figure 2).

There were no relevant changes to the prescriptions in the second evaluation phase, with the predominance of medication "if necessary" to control pain and nausea (at all levels) remaining, as well as the absence of a specific prescription for the control of other symptoms.

The most prescribed medications for mild pain relief were non-opioid painkillers, while for moderate and strong pain non-opioid painkillers and weak opioids were used. The anti-emetic prescribed the most was metoclopramide. For control of asthenia, the most prevalent prescription was corticotherapy, and for dyspnea, oxygen therapy and bronchodilators. Benzodiazepines were the most prescribed anxiolytics.

It should be noted that the researcher contacted the attending physician of 116 patients (69\%) to report on worsening of symptoms or presence of moderate or severe symptoms $(\mathrm{ESAS} \geq 4)$. 


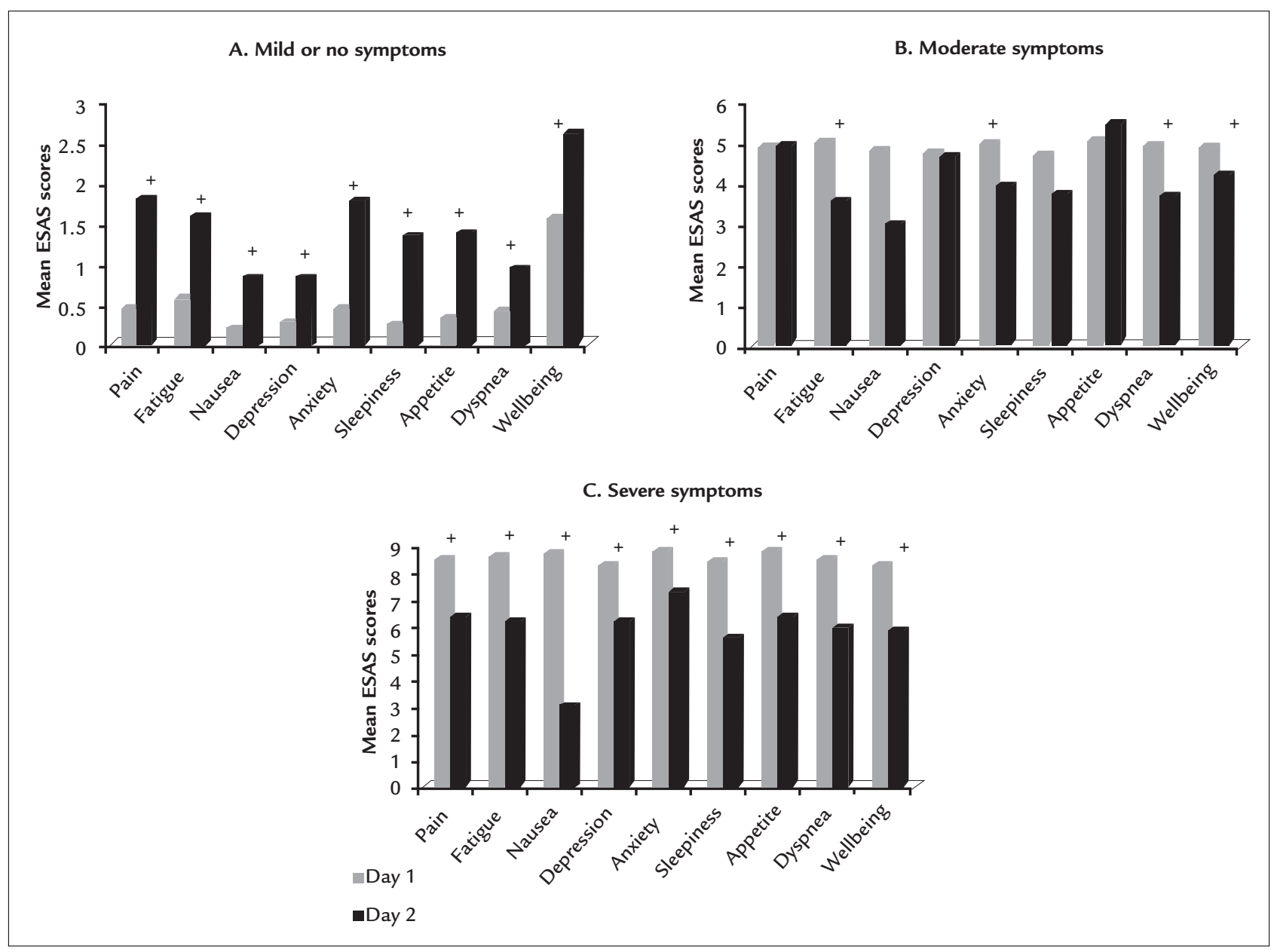

FIGURE 1 Progression of symptoms on day 1 (D1) and day 2 (D2) according to the ESAS scale.

\section{Discussion}

The results of this study revealed that patients in the clinical wards of the HU-UFSC were mostly male and suffered from non-cancerous chronic-degenerative diseases. About $30 \%$ had a PPS $\leq 60$, with a direct relationship between PPS score and patient age. The patients' symptoms were generally poorly controlled, with intermittent administration (if necessary) of medications. This was more prevalent in patients presenting mild symptoms.

In our study, we found that although there was a discreet predominance of population aged less than 60 years (52.9\%), the median age was close to this age group (55.7 years) and composed mainly by males (58.9\%). This reflects the demographic pattern of the country, given that the current trend is toward an increase in age of the population. ${ }^{21}$ It should be remembered that greater longevity leads to a greater number of chronic conditions with consequent reduction in functionality (PPS $\leq 60) .^{22,23}$ This fact was found in the study, where there was a direct relationship between lower functionality and age older than 60 years. The low number of patients with pathologies of cancerous origin in this study can be explained by the HU-UFSC not being a reference center for this type of disease.

It should be noted that approximately $30 \%$ of the study participants had a PPS $\leq 60$, meaning a very low degree of functionality, and that would indicate the need for prioritization of palliative care. Glare et al. in their study on the perspective of physicians in relation to the survival of patients with terminal illnesses showed that physicians are generally more optimistic and often overestimate the survival of patients. ${ }^{24}$ The study by Lau et al. (2009) showed that the PPS is an important predictor of survival for patients diagnosed with cancerous and noncancerous diseases showing a relationship between PPS score and the number of days survived by patients. Patients with a PPS of $30 \%$ survived an average of 32 days, those with a PPS of $40 \%$ survived 65 days and for those with a PPS of $60 \%$ survival was 104 days. ${ }^{18}$ In a study by 


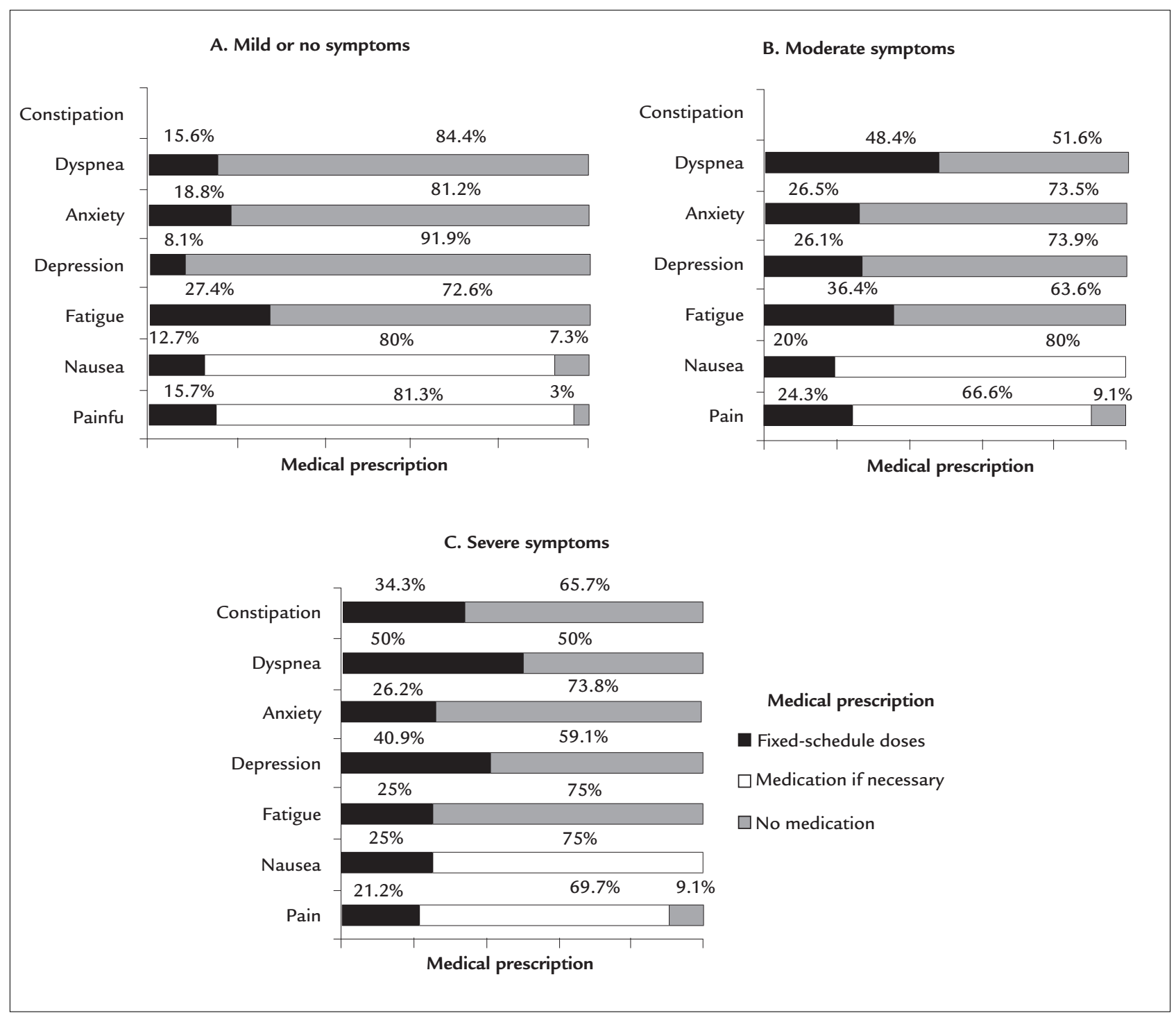

FIGURE 2 Medical prescription according to the intensity of symptoms.

Weng et al., which assessed the relationship between PPS and days survived by patients with cancerous diseases, the survival rate found was lower: PPS $\leq 30 \%-6$ days, PPS $=40 \%-19$ days, $50 \% \geq P P S-34$ days. ${ }^{19}$ In view of these results, it can be suggested that the PPS scale is used routinely as a predictive prognosis factor. The prognostic evaluation is important for the implementation of PC and, consequently, for adequate control of the symptoms of patients, with subsequent improvement of their quality of life. ${ }^{18-20}$

An important piece of data noted in this study was that patients with mild symptoms presented worsening of such in the second assessment conducted by the researcher. This fact allows us to deduce that these symptoms are poorly diagnosed and, thus, poorly controlled.
It was also detected that some of them are more underestimated than others and that some are not even diagnosed. Patients with fatigue, depression, anxiety, dyspnea and constipation did not receive any kind of treatment, and prescription for pain control was "if necessary" only, which is not as recommended in the literature reviewed..$^{25,26}$

The results of this study showed that the patients had a high prevalence of pain symptoms (57.1\%), fatigue $(57.1 \%)$ and dyspnea (44.6\%). However, the most prevalent was anxiety $(65.4 \%)$. It is indisputable that the presence of symptoms interferes with a person's quality of life. ${ }^{27}$ The lack of investigation and characterization of these symptoms, as well as indifference to manage them, either due to lack of knowledge by the physician or health system limitations, often cause inadequate control. $3,7,10,16$ 
As a result, the complaint is often underestimated and treatment becomes inappropriate even for potentially treatable symptoms. ${ }^{16}$ According to Honea et al., symptoms are related to each other; for example, pain causing fatigue and fatigue causing depression and decreased pain tolerance. ${ }^{28}$ According to the authors, some symptoms increase the intensity of others, creating a cycle of intense and persistent symptoms. Therefore, continuous and systematic assessment, the implementation of treatment, and constant evaluation of the response to the proposed interventions are essential for proper care of the patient. ${ }^{28,29}$

Regarding pain symptoms, it is interesting to point out that patients with mild pain in the first evaluation of the study progressed with significant worsening during hospitalization. On the other hand, those with severe pain showed significant improvement of the symptom in the second evaluation. There is a debate regarding what reason could justify this fact. It can be inferred that patients with severe symptoms requested more medications prescribed "if necessary", thereby obtaining greater relief. On the other hand, those with mild symptoms may have had their suffering underestimated. This may be due to a cultural trait that considers the demonstration of suffering as a sign of weakness. ${ }^{30,31}$ By feeling mild pain, patients might want to demonstrate to their families that they are well, strong, and therefore do not require medication. ${ }^{31}$ According to Cynthia Sarti, ways of feeling and expressing pain are governed by cultural codes, and pain itself, as a human fact, is constituted by the meanings conferred by the collective. Thus, there may be greater or lesser tolerance of pain, depending on what is expected of the individual, according to their social position. For many people, bearing pain in silence can be a sign of virility. How the professional reacts in relation to pain and the manifestations of the patient will also influence the patient's reaction to treatment. ${ }^{30,31}$ Another issue that must be taken into consideration is the role of health professionals in pursuing the symptom and accepting what the patient reports. The evaluation and systematic recording of pain complaints after other vital signs constitute essential data in order to adequately treat the suffering of the patient. Given that patients may experience different levels of pain and that self-assessment is the safest indicator of the intensity of the symptom, it is crucial to believe and promptly respond to a patient's referred pain. ${ }^{32}$ According to Davis and Walsh, patients who have pain intensity assessed and recorded systematically present a considerable reduction of pain compared to those who are not monitored..$^{33}$ Thus, it is important to emphasize the need for adequate assessment of the pain, which should be considered as the fifth vital sign and systematically controlled. ${ }^{32,33}$

A curious fact in this study was that patients with severe symptoms, even if not receiving specific drug treatment for fatigue, depression and anxiety, showed improvement of such. According to the literature, treatment of a single symptom, such as pain, can contribute to the relief of other symptoms. The relief of any malaise can improve the patient's perception about the treatment and decrease fear related to the disease, thereby improving other related symptoms. ${ }^{28}$ Another issue that interferes with the presentation of symptoms is the doctor-patient relationship. A good interaction not only has positive effects on satisfaction of users and the quality of health services, but also exerts a direct influence on the state of health of patients. ${ }^{31}$ In our country, depression has become increasingly common in the elderly due to social isolation or institutionalization of individuals considered incapacitated. Often, even when living in a family environment, they may be suffering from loneliness, lack of support, affection, care and attention. ${ }^{27}$ Associated comorbidities may also interfere with self-esteem because of changes in emotional state, such as sadness, discouragement, demotivation, nervousness, boredom, loss of pleasure, insecurity, a feeling of worthlessness and dissatisfaction with self-image. ${ }^{27}$ As such, by the mere fact of such individuals being in a hospital, with other people nearby and knowing that they are being watched over, can lead to easing of their depressive symptoms. Although most patients in this study were not actually elderly, the suffering created by decompensation and by the difficulty of outpatient treatment of chronic degenerative diseases could lead to depression. On the other hand, hospitalization, which would ensure the most efficient service, could improve this symptom.

In relation to the control of symptoms, in this study there was a prevalence of "if necessary" prescriptions. Even for patients with severe symptoms, medication to treat pain and nausea were not prescribed with fixed schedules. This result disagrees with that indicated in the literature reviewed. According to the NCCN Guidelines - Adult Cancer Pain, for severe pain there should be a fixed prescription of strong opioids, with additional doses for any new episodes of pain. ${ }^{25}$ Patients who complain of mild pain should also receive fixed schedule treatment with opioid painkillers, such as NSAIDS or acetaminophen, with the administration of low doses of short duration opioids also considered. For moderate pain, a fixed prescription of weak opioids is recom- 
mended. The use of adjuvant medication should be considered at any stage in the treatment of pain..$^{25}$

Unfortunately, knowledge of palliative care is still not widespread in the Brazilian medical context. This statement corroborates with the observation of this study, where only one patient out of all 168 participants had the need for this care explicitly stated in their records. This is in addition to the 45 patients who had low functionality (PPS $\leq 60)$ and would have been indicated for palliative assessment. In the mind of many physicians, there still exists the idea that palliative care is a measure employed when there are no more therapeutic strategies to be followed for the patient; however, in fact, palliative care is a special type of health treatment centered on the patient and their family, which focuses on the effective management of pain and other distressing symptoms, primarily targeting quality of life. These precautions include psychosocial and spiritual care according to the beliefs, needs, values and culture of the patient and their family, ${ }^{9,25}$ and serve to relieve the suffering at all stages of the disease, without being limited to the final stages of life. ${ }^{9-14,25}$ Palliative care should be started upon the diagnosis of an incapacitating disease, with high probability of death, and practiced concurrently with curative/restorative treatment, with its focus prioritized on the course of the disease..$^{9-14,25}$

This study focused primarily on the analysis of symptoms demonstrated subjectively by the ESAS, which represents a limitation on the general evaluation of the patients, because the patient-disease binomial covers dimensions far beyond the nine symptoms evaluated. Thus, for a more complete study it would be interesting to investigate the symptoms, as well as to analyze spiritual and psychological issues, the patient's knowledge of the pathology, their needs and the needs of their family members and caregivers.

\section{Conclusion}

The results of this study made it possible to conclude that most of the patients on the wards of the HU-UFSC internal medicine clinic suffered from non-cancerous chronic degenerative diseases. The most prevalent symptoms were anxiety, pain, fatigue and dyspnea. There was a worsening of symptoms of mild intensity during the hospitalization, which shows that they were poorly controlled. The predominant form of drug prescription for the control of symptoms of all intensities was "if necessary." Around thirty percent of the patients had a low functional status (PPS $\leq 60)$ and only one patient received the preferential palliative approach in his/her treatment.
It can be deduced that it is necessary to raise awareness of the entire health team about the importance of their commitment to achieving success in the control of patient symptoms. Each symptom is subjective and unique to the patient experiencing it, and poorly controlled symptoms can compromise the entire treatment. Therefore, a systematic and continuous approach is a prerequisite for proper management of the symptoms and successful treatment of the disease. For that, spreading among health professionals methods that enable a detailed investigation of patient symptoms, such as the systematic use of assessment scales, is essential.

The results of this study allow us to suggest a policy of continued education for proper control of symptoms and greater disclosure of palliative care, more specifically palliative actions aimed at optimizing the treatment of patients admitted to the hospital under study.

\section{Resumo}

Avaliação dos sintomas e tratamento prescrito a pacientes internados

Objetivo: avaliação da presença de sintomas e adequabilidade do tratamento nos pacientes internados nas enfermarias clínicas do Hospital Universitário da Universidade Federal de Santa Catarina (HU-UFSC). Verificação dos pacientes elegíveis para cuidados paliativos (CP).

Método: estudo de coorte prospectivo que avaliou pacientes nas primeiras 48 horas da internação (D1) e após 48 horas (D2). No D1, foram aplicadas escalas de performance paliativa e de avaliação dos sintomas (PPS/ESAS). Também verificou-se o tratamento estabelecido para o controle dos sintomas detectados. No D2, a ESAS foi reaplicada, sendo revisada a prescrição médica. Quando constatada a presença de sintomas graves, o médico assistente foi informado. Foram elegíveis para a priorização de $\mathrm{CP}$ os pacientes que apresentaram PPS $\leq 60$. Para a análise estatística, foram utilizados os testes $T$ de Student e $\chi^{2}$.

Resultados: foram estudados 168 pacientes, dos quais $26,8 \%$ tinham uma PPS $\leq 60$. CP foram descritos em um prontuário. Os doentes com sintomas leves referiram piora significante na segunda avaliação, destacando-se piora da dor $(32,3 \%)$ e do bem-estar (49,3\%). Os sintomas considerados graves apresentaram melhora significante. Não houve controle da dor relatada como moderada. As prescrições para o controle da dor eram predominantemente "se necessário", prevalecendo o uso de analgésicos não opioides e opioides fracos. O médico assistente foi informado sobre 116 (69\%) pacientes com ESAS $\geq 4$. 
Conclusão: o controle dos sintomas, principalmente os leves, foi insatisfatório. A prescrição médica foi inadequada para o controle da dor e inexistente para alguns sintomas referidos. Não houve priorização adequada dos CP. Há necessidade de otimização e divulgação dos CP entre profissionais da saúde.

Palavras-chave: cuidados paliativos, avaliação de sintomas, escalas, dor.

\section{References}

1. Rezende EM, Sampaio IBM, Ishitani LH. Causas múltiplas de morte por doenças crônico-degenerativas: uma análise multidimensional. Cad Saúde Pública. 2004; 20(5):1223-31.

2. Kalache A, Veras RP, Ramos LR. O envelhecimento da população mundial. Um desafio novo. Rev Saúde Pública. 1987; 21(3):200-10.

3. Palma A, Del Río I, Bonati P, Tupper L, Villarroel L, Olivares P, et al. Frecuencia y pesquisa de síntomas en pacientes crónicos en fase avanzadas en um hospital clínico. ¿Existe concordancia entre pacientes y medicos? Rev Méd Chile. 2008, 136:561-9.

4. Grudzen CR, Richardson LD, Morrison M, Cho E, Morrison RS. Palliative care needs of seriously ill, older adults presenting to the emergency department. Acad Emerg Med. 2010; 17(11):1253-57.

5. Rhondali W, Huid D, Kim SH, Kilgore K, Kang JH, Nguyen L, et al. Association between patient-reported symptoms and nurses' clinical impressions in cancer patients admitted to an acute palliative care unit. J Palliat Med. 2012; 15(3):301-07.

6. Riechelmann RP, Krzyzanowska MK, O'Carroll A, Zimmermann C. Symptom and medication profiles among cancer patients attending a palliative care clinic. Support Care Cancer. 2007; 15(12):1407-12.

7. Sigurdardottir KR, Haugen DF. Prevalence of distressing symptons in hospitalised patients on medical wards: a cross-sectional study. BMC Palliat Care. 2008; 7:16.

8. Pantilat SZ, O'Riordan DL, Dibble SL, Landefelt CS. An assessment of the screening performance of a single-item measure of depression from Edmonton Symptom Assessment Scale among chronically ill hospitalized patients. J Pain Symptom Manage. 2012; 43(5):866-73.

9. Moritz RD. Cuidados paliativos nas unidades de terapia intensiva. São Paulo: Atheneu, 2012.119p.

10. Puntillo KA, Arai S, Cohen NH, Grooper MA, Neuhaus J, Paul SM, et al. Symptoms experienced by intensive care unit patients at high risk of dying. Crit Care Med. 2010; 38(11):2155-60.

11. Walling AM, Asch SM, Lorenz KA, Roth CP, Barry T, Kahn KL, et al. The quality of care provided to hospitalized patients at the end of life. Arc Intern Med. 2010; 170(12):1057-63.

12. Firmino TM. Avaliação do estado funcional e dos sintomas apresentados por pacientes internados na enfermaria clínica de um hospital universitário. [End of course assignment]. Florianópolis: Universidade Federal de Santa Catarina, Curso de Medicina, 2011.

13. Moritz RD, Deicas A, Calpabo ML, Fortes DN, Kretzer LP, Lago P, et al. II Fórum do "Grupo de Estudos do Fim da Vida do Cone Sul": definições, recomendações e ações integradas para cuidados paliativos na unidade de terapia intensiva de adultos e pediátrica. RBTI 2011; 23(1):24.

14. World Health Organization. Essential Medicines in Palliative Care. Geneva: WHO, 2013

15. Academia Nacional de Cuidados Paliativos. Manual de cuidados paliativos. Rio de Janeiro: Diagraphic, 2009. 320p.

16. Spichiguer E, Müller-Fröhlich C, Denhaerynck K, Stoll H, Hantikainen V, Dodd M. Symptom prevalence and changes of symptoms over ten days in hospitalized patients with advanced cancer: a descriptive study. Eur J Oncol Nurs. 2011; 15(2):95-102.

17. Seow H, Barbarena L, Dudgeon D, Howell D, Husain A, Atzema C, et al. The association of the palliative performance scale and hazard of death in an ambulatory cancer population. J Palliat Med. 2013; 16(2):156-62.

18. Lau F, Maida V, Downing M, Lesperance M, Karlson N, Kuziemsky C. Use of the Palliative Performance Scale (PPS) for end-of-life prognostication in a palliative medicine consultation service. J Pain Symptom manage. 2009; 37(6):965-72.

19. Weng LC, Huang HL, Wilkie DJ, Hoenig NA, Suarez ML, Marschke M, et al. Predicting survival with the Palliative Performance Scale in a minorityserving hospice and palliative care program. J Pain Symptom Manage. 2009; 37(4):642-48

20. Bret EP. La excelencia de los cuidados paliativos. Cuad Bioét. 2011; 22(3):535-41.

21. Ministério da Saúde, Departamento de Informática do SUS (DATASUS) Sistema de Informação da Atenção Básica. 2012. [cited 2014 Apr]. Available from: http://tabnet.datasus.gov.br/cgi/deftohtm.exe?idb2012/a01.def

22. Correia LA, Leite IC, Machado CJ. Conceituando e mensurando a incapacidade funcional da população idosa: uma revisão de literatura. Ciênc Saúde Coletiva. 2008; 13(4):1199-207.

23. George E, Kolt G, Rosenkranz R. Chronic disease, physical activity and sitting time in middle- aged Australian males: findings from the 45 and Up Study. J Sci Med Sport. 2012; 15(Suppl 1):S81.

24. Glare P, Virik K, Jones M, Hudson M, Eychmuller S, Simes J, et al. A systematic review of physicians' survival predictions in terminally ill cancer patients. BMJ. 2003; 327(7408):195-8.

25. Swarm RA, Paice J, Anghelescu DL, Benedetti C, Cleeland C, deLeon-Casasola OA, et al. NCCN Clinical Practice Guidelines in Oncology - Adult Cancer Pain. Version 2.2014. [cited 2014 Apr 18]. Available from: http://www.nccn. org/professionals/physician_gls/pdf/pain.pdf

26. Chang VT, Arnold RM, Dizon DS. Approach to symptom assessment in palliative care. [cited $2014 \mathrm{Apr} 10]$. Available from: http://www.uptodate. com

27. Vitorelli E, Pessini S, Silva MJP. A auto-estima de idosos e as doenças crônicodegenerativas. Revista Brasileira de Ciências do Envelhecimento Humano. 2005; $2(1): 102-14$

28. Honea N, Brant J, Beck S. Treatment-related symptom clusters. Semin Oncolo Nurs. 2007; 23(2):142-51.

29. Solano JP, Gomes B, Higginson IJ. A comparison of symptom prevalence in far advanced cancer, AIDS, heart disease, chronic obstructive pulmonary disease and renal disease. J Pain Symptom Manage. 2006; 31(1):58-69.

30. Sarti C. A dor, o indivíduo e a cultura. Saúde e Sociedade. 2001; 10(1):3-13.

31. Fontes $\mathrm{KB}$, Jacques $\mathrm{AE}$. O papel da enfermagem frente ao monitoramento da dor como $5^{\circ}$ sinal vital. Cienc Cuid Saude. 2007; 6(Suppl. 2):481-87.

32. Davis MP, Walsh D. Cancer pain: how to measure the fifth vital sign. Cleve Clin J Med. 2004; 71(8):625-32.

33. Caprara, Rodrigues J. A relação assimétrica médico-paciente: repensando o vínculo terapêutico. Ciência \& Saúde Coletiva. 2004; 9(1):139-46. 